\title{
Clinical Outcome and Echocardiographic Evaluation of Inferior Myocardial Infarction with Right Ventricular Involvement
}

\author{
B Guha, AAS Majumder, MNA Chowdhury, MM Hossain, AK Mandal \\ Department of Cardiology, NICVD, Dhaka.
}

\begin{abstract}
Key Words : Background : Acute right ventricular myocardial infarction complicates inferior wall myocardial Electrocardiography, Echocardiography, Right ventricular infarction, Acute myocardial infarction . infarction with an incidence of $14-84 \%$. ECG is the cornerstone in initial diagnosis as it is cost effective and done easily. Echocardiographic analysis of the right ventricular involvement can shed light on the severity of the disease. Hence we aimed to study right ventricular infarction in acute inferior wall myocardial infarction using right precordial lead as well as echocardiography.

Methods: Present study is based on the analysis of 100 patients admitted to Coronary care unit of the National Institute of Cardiovascular Diseases \& Hospital during July 2010 to June 2011, with acute inferior wall myocardial infarction. 12 lead ECG with thorough physical examination was done along with right precordial mapping. $S T^{3} 1 \mathrm{~mm}$ in V4R was initial diagnostic of right ventricular involvement followed by echocardiographic assessment of $R V$ and LV within 24 hours.

Results: A total of 50 patients showed right ventricular involvement with V4R being the sensitive lead. Echocardiography showed mean RVEF of patients with $29.5 \% \pm 9.5$ in comparison of $44.9 \% \pm 12.2$ without right ventricular involvement. Right ventricular involvement presented with bradycardia (40\%) and hypotension, 80\% Kussmaul's sign, 14\% with complete heart block. Mortality in right ventricular involvement was 6 times higher than without right ventricular involvement $(12 \%)$.

Conclusion: Clinical signs and symptomatology are not fully diagnostic of RVI in inferior wall acute MI. ECG can diagnose (using right precordial mapping) this condition very early. Echocardiography help to assess the right ventricular function high-risk groups for aggressive management like primary PCI. Early diagnosis will help in careful monitoring and management of such cases.
\end{abstract}

(Cardiovasc. j. 2012; 4(2): 132-138)

\section{Introduction:}

Coronary heart disease (CHD) is a major cause of mortality, and is a global health problem reaching epidemic proportions in both developed as well as developing countries. ${ }^{1}$ The South Asian countries of India, Pakistan, Bangladesh, Srilanka, and Nepal contribute the highest proportion of the burden of cardiovascular diseases (CVDs) compared to any other region globally. ${ }^{2,}, 3,4$ Estimates from the Global burden of Disease Study suggests that by the year 2020 this part of the world will have more individuals with atherosclerotic cardiovascular disease than any other region. ${ }^{4}$

CHD will be the major health and number one killer disease in developed countries like USA, increased prevalence and excess mortality in CHD was documented by several studies. The prevalence of
CHD was estimated as 3.3/1000 in 1976 and 17.2/ 1000 in 1986 indicating 5 folds increase of the disease in 10 years. AMI is a major component of acute coronary syndrome which usually due to anterior or inferior wall involvement. The presentation of acute myocardial infarction is different depending on the coronary artery involved. Right ventricular infarction (RVI) accompany extensive inferiorposterior infarctions. Inferior wall MI results from either right coronary artery (RCA) or left circumflex coronary artery (LCX) occlusion. RCA predominantly supply the part of conducting system, right atrium, right ventricle, part of left ventricle and the posteromedial papillary muscle. Occlusion of RCA may cause RV infarction with hypotension, cardiogenic shock, and different types of conduction disturbance, mitral regurgitation and sudden death.

Address of Correspondence: Dr Binoy Guha. Department of Cardiology, National Institute of Cardiovascular Diseases, Dhaka, Bangladesh. 
Clinical detection of RV infarction was done by searching raised jugular pressure, clear lung field, low cardiac output which resembles many clinical situations like chronic obstructive pulmonary disease, pulmonary stenosis, pulmonary hypertension, acute pulmonary embolism. ${ }^{5}$

The occurrence of an inferior left ventricular infarction involving the right ventricle ranges from $14 \%$ to $84 \%$, but is typically thought to be about $50 \% .{ }^{6}$ Echocardiography has been very useful in detecting right ventricular dilatation and segmental wall motion abnormalities characteristic of right ventricular infarction $\mathrm{RV}$ dilatation may be defined as a ratio of $R V$ end-diastolic area to $L V$ end-diastolic area of - $0.6 \mathrm{RV}$ dilatation is severe when the ratio is-1.0. ${ }^{7}$

The mortality of patient with only inferior wall acute myocardial infarction (AMI) is $5-6 \%$, which increases to $25-30 \%$ along with the involvement of right ventricle. The patients with RVI had a higher in hospital mortality rate ( $31 \%$ vs $6 \%, \mathrm{p}<0.001)$ and a higher incidence of major

in-hospital complications ( $64 \%$ vs . $28 \%$,p<0.001) than did those without RVI. So the patient with inferior wall AMI, site of culprit lesions is an important determinant of outcome. ${ }^{8}$ The patient with anterior myocardial infarction had a substantially worse in hospital and follow up clinical course compared with those with inferior MI . Right ventricular infarction (RVI) occurs in 20 to $50 \%$ of patients with inferior MI. Inferior MI with RVI has a high mortality rate of $25-30 \%$ as compared with only $6 \%$ for inferior MI without RVI . There is a wide range of hemodynamic disturbance associated with RVI starting with asymptomatic course to severe hypotension , shock, fatal arrhythmias with sudden death.

\section{Materials and methods:}

A cross sectional study was carried out conducted in the department of cardiology, National Institute of Cardiovascular Diseases (NICVD), Dhaka, Bangladesh from January 2011 to June 2011.Patients of acute inferior myocardial infarction with or without right ventricular involvement at NICVD during the study period was the study population.

\section{Enrollment of subjects :}

\section{Methodology}

Patients who presented with acute inferior myocardial infarction within 12 hours and were admitted in NICVD were included in the study. Patients with previous myocardial infarction, concomitant acute anterior myocardial infarction, valvular heart diseases, pacemaker, bundle branch block, cardiomyopathies, congenital heart disease and corpulmonale were excluded from the study. Informed written consent was taken from each subject before enrollment. Evaluation of the patients by taking meticulous history \& detailed clinical examination and data was recorded in a pre-designed form. Demographic profile (Age, sex , height, weight), Clinical profile (Pulse ,BP ,NYHA functional class, cardiogenic shock, arrhythmia , heart block), Risk factor profile(Smoking, hypertension, diabetes mellitus (DM), dyslipidemia \& family history of coronary artery disease), Medications (Present and recent use of drugs), ECG, with right sided ECG on admission and within $12 \mathrm{hrs}$ of the onset of symptoms was recorded. Admission ECG along with right sided ECG was evaluated in all patients with inferior MI. If patients was received thrombolytic, then post thrombolytic ECG was evaluated one and half hour after thrombolysis.

Patients was divided into two groups based on presence or absence of ST segment elevation in lead V4R or V3R.

Group -I: patients with ST segment elevation in V4R or V3R (with RV infarction).

Group-II: patients with isoelectric ST segment in V4R or V3R (without RV infarction)

Patients were evaluated by 2D, M-mode and Doppler echocardiography. Standard echocardiographic measurement was done and averaged in 4 cardiac cycles. Echocardiography was done in all patients within 72 hours of onset of chest pain to look for left ventricular ejection fraction, any mechanical complications. Variables specially included LVID(d), LVID (s), regional wall motion abnormality (RWMA), left ventricular ejection fraction (LVEF). Echocardiography of right ventricular function was done biplane Simpson's method in apical four chamber view and other views. 


\section{Statistical analysis}

All data were recorded systematically in preformed data collection form and data were expressed as mean and standard deviation and qualitative data as frequency distribution and percentage. Statistical analysis was performed by using SPSS version 16. 95\% confidence limit was taken. Probability value $<0.05$ was considered as level of significance.

\section{Observations and Results}

This cross sectional study was conducted in the department of cardiology, NICVD, Dhaka from January 2011 to June 2011 . Total 100 subjects were included in this study. The findings of the study are presented here.

Table I showed that about d" 40 years old patients were $16 \%$ in Group I and 18\% in Group II. Group I had $26 \%$ and group II had $40 \%$ of patients between (41-50) years. Next (51-60) years were $34 \%$ and $26 \%$ in Group I and Group II respectively. Patients of $>$ 60 years were $24 \%$ and $16 \%$ in Group I and Group II respectively. The age distribution was almost identical between patients with and without right ventricular involvement $(54.5 \pm 11.2$ vs50.2 \pm 13.4 years. $\mathrm{P}=0.08$ ).

\section{Table I}

Age distribution of the study population ( $n=100)$

\begin{tabular}{lcccccc}
\hline $\begin{array}{l}\text { Age group } \\
\text { (year) }\end{array}$ & \multicolumn{2}{c}{$\begin{array}{c}\text { Group I } \\
(\mathrm{n}=50)\end{array}$} & & \multicolumn{2}{c}{$\begin{array}{c}\text { Group II } \\
(\mathrm{n}=50)\end{array}$} & Pvalue* \\
\cline { 2 - 3 } \cline { 5 - 6 } & Number & $\%$ & & Number & $\%$ & \\
\hline$\leq 40$ & 8 & 16.0 & 9 & 18.0 & 0.79 \\
$41-50$ & 13 & 26.0 & 20 & 40.0 & 0.13 \\
$51-60$ & 17 & 34.0 & 13 & 26.0 & 038 \\
$>60$ & 12 & 24.0 & 8 & 16.0 & 0.31 \\
Mean \pm SD & $54.5 \pm 11.2$ & $50.2 \pm 13.4$ & & 0.08 \\
\hline
\end{tabular}

Group I: With RVI, Group II : Without RVI

*p value reached from unpaired t-test
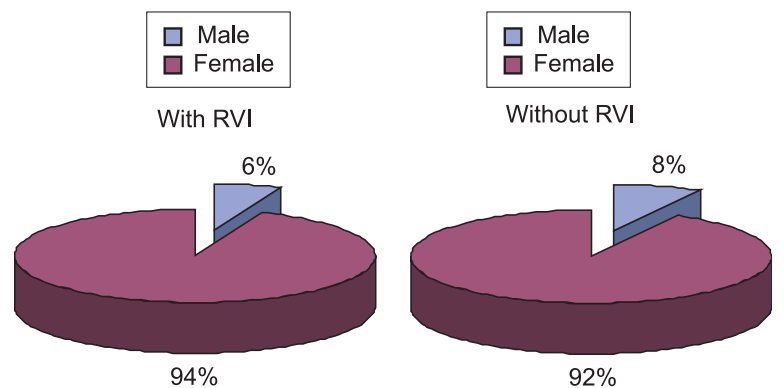

Fig.-1: Pie diagram showed sex distribution of study populations between two groups.
Majority of patients were male in Group I and Group II (94\% and 92\% respectively). Statistically not significant mean sex difference was found between patients of study groups $(p>0.05)$

Table II

Distribution of risk factors between two groups $(n=100)$

\begin{tabular}{|c|c|c|c|c|c|c|}
\hline \multirow[t]{2}{*}{ Risk factor } & \multicolumn{3}{|c|}{$\begin{array}{c}\text { Group I } \\
(\mathrm{n}=50)\end{array}$} & \multicolumn{2}{|c|}{$\begin{array}{c}\text { Group II } \\
(\mathrm{n}=50)\end{array}$} & \multirow[t]{2}{*}{ Pvalue } \\
\hline & Nun & mber & $\%$ & Number & $\%$ & \\
\hline Smoking & & 44 & 88.0 & 34 & 68.0 & 0.01 \\
\hline $\begin{array}{l}\text { Diabetes } \\
\text { Mellitus }\end{array}$ & & 24 & 48.0 & 10 & 20.0 & 0.003 \\
\hline Hypertensi & & 16 & 32.0 & 23 & 46.0 & 0.15 \\
\hline Dyslipidem & mia & 7 & 14.0 & 8 & 16.0 & 0.77 \\
\hline $\begin{array}{l}\text { Family his } \\
\text { of CAD }\end{array}$ & story & 25 & 50.0 & 15 & 30.0 & 0.04 \\
\hline
\end{tabular}

Group I: With RVI

Group II : Without RVI

${ }^{*}$ p value were analyzed using Pearson Chi-Square Test.

Among the Group I smoking (88\%) was the most common risk factor followed by family history of CAD (50\%), diabetes mellitus (48\%), hypertension (32\%) and dyslipidemia (14\%). On the other hand among Group II patient highest percentage had smoking (68\%), followed by

hypertension (46\%), family history of CAD (30\%), diabetes mellitus (20\%) and dyslipidemia (16\%). There were statistically significant risk factors difference between smoking, diabetes mellitus and family history of CAD in between study groups $(\mathrm{p}<0.05)$.

\section{Table III}

Base- line clinical parameters of the study population $(n=100)$

\begin{tabular}{|c|c|c|c|c|c|}
\hline \multirow[t]{2}{*}{ Parameters } & \multicolumn{2}{|c|}{$\begin{array}{l}\text { Group I } \\
(\mathrm{n}=50)\end{array}$} & \multicolumn{2}{|c|}{$\begin{array}{c}\text { Group II } \\
(\mathrm{n}=50)\end{array}$} & \multirow[t]{2}{*}{ Pvalue } \\
\hline & \multicolumn{2}{|c|}{ Mean \pm SD } & \multicolumn{2}{|c|}{ Mean \pm SD } & \\
\hline Pulse & \multicolumn{2}{|c|}{$68.0 \pm 14.7$} & \multicolumn{2}{|c|}{$74.8 \pm 14.6$} & $0.04^{*}$ \\
\hline Systolic BP & \multirow{2}{*}{\multicolumn{2}{|c|}{$\begin{array}{l}94.6 \pm 30.4 \\
66.7 \pm 14.8\end{array}$}} & \multirow{2}{*}{\multicolumn{2}{|c|}{$\begin{array}{c}115.4 \pm 17.8 \\
73.1 \pm 13.5\end{array}$}} & $0.001 *$ \\
\hline \multirow[t]{2}{*}{ Diastolic BP } & & & & & $0.05^{*}$ \\
\hline & No & $\%$ & No & $\%$ & \\
\hline JVP Raised & 37 & 74.0 & 13 & 26 & $0.001^{* *}$ \\
\hline $\begin{array}{l}\text { Lungs bases } \\
\text { clear }\end{array}$ & 35 & 70.0 & 13 & 26 & $0.001^{* *}$ \\
\hline
\end{tabular}

Group I: With RVI, Group II : Without RVI

* p value reached from independent sample t-test.

**p value were analyzed using Pearson Chi-Square Test. 
Table III showed that mean pulse rate was $68.0 \pm 14.7$ vs. $74.8 \pm 14.6 / \mathrm{min}$ between Group I and Group II respectively. Mean difference of systolic blood pressure $94.6 \pm 30.4 \mathrm{mmof} \mathrm{Hg}$ vs $115.4 \pm 17.8 \mathrm{~mm}$ of $\mathrm{Hg}$ were found between Group I and Group II. Mean difference of diastolic blood pressure was found $66.7 \pm 14.8$ vs $73.1 \pm 13.5 \mathrm{~mm}$ of $\mathrm{Hg}$ between groups. Raised JVP had 74\% in Group I and 26\% in Group II. Lungs bases were clear $70 \%$ cases in Group I and $26 \%$ in Group II respectively. All these differences were statistically significant $(p<0.05)$.

Table IV

Comparison of echocardiography of the left ventricle between the groups $(n=100)$

\begin{tabular}{lcccc}
\hline Parameters & $\begin{array}{c}\text { Group I } \\
(\mathrm{n}=50)\end{array}$ & & $\begin{array}{c}\text { Group II } \\
(\mathrm{n}=50)\end{array}$ & p value* \\
\cline { 2 - 2 } & Mean $\pm \mathrm{SD}$ & & Mean $\pm \mathrm{SD}$ & \\
\hline LVEF & $50.6 \pm 6.6$ & & $53.0 \pm 8.5$ & 0.12 \\
LVIDd & $46.7 \pm 5.5$ & & $47.3 \pm 6.1$ & 0.65 \\
LVIDs & $34.7 \pm 4.9$ & & $35.2 \pm 7.8$ & 0.70 \\
\hline
\end{tabular}

Group I: With RVI, Group II : Without RVI

*p value reached from sample t-test

Above table showed that mean of left ventricular ejection fraction(LVEF) was $50.6 \pm 6.6$ to $53.0 \pm 8.5$ in between Group I and Group II respectively ( $\mathrm{p}=0.12)$. Left ventricular internal dimension in diastole (LVIDd) was $46.7 \pm 5.5$ to $47.3 \pm 6.1$ respectively between group ( $\mathrm{p}=0.65)$. Left ventricular internal dimension in systole (LVIDs) was $34.7 \pm 4.9$ to $35.2 \pm 7.8$ respectively between group $(\mathrm{p}=0.70)$.

\section{Table V}

Comparison of echocardiography of Right ventricle between two groups $(n=100)$

\begin{tabular}{|c|c|c|c|c|c|}
\hline \multirow[t]{2}{*}{ Parameters } & \multicolumn{2}{|c|}{$\begin{array}{c}\text { Group I } \\
(\mathrm{n}=50)\end{array}$} & \multicolumn{2}{|c|}{$\begin{array}{c}\text { Group II } \\
(\mathrm{n}=50)\end{array}$} & \multirow[t]{2}{*}{ Pvalue } \\
\hline & \multicolumn{2}{|c|}{ Mean $\pm \mathrm{SD}$} & \multicolumn{2}{|c|}{ Mean $\pm \mathrm{SD}$} & \\
\hline $\begin{array}{l}\text { Right } \\
\text { ventricular } \\
\text { diameter } \\
\text { (in diastole) }\end{array}$ & \multicolumn{2}{|c|}{$29.3 \pm 5.6$} & \multicolumn{2}{|c|}{$24.3 \pm 5.4$} & $0.001^{*}$ \\
\hline \multirow{2}{*}{$\begin{array}{l}\text { Right } \\
\text { ventricular } \\
\text { EF }\end{array}$} & \multicolumn{2}{|c|}{$29.5 \pm 9.5$} & \multicolumn{2}{|c|}{$44.9 \pm 12.2$} & $0.001^{*}$ \\
\hline & No & $\%$ & No & $\%$ & \\
\hline TR & 20 & 40.0 & 4 & 8.0 & $0.001 * *$ \\
\hline MR & 6 & 12.0 & 1 & 2.0 & $0.05^{* *}$ \\
\hline
\end{tabular}

Group I: With RVI, Group II : Without RVI

* p value reached from independent sample t-test. **p value were analyzed using Pearson ChiSquare Test.
Above table shows that mean of right ventricular diameter (in diastole) had $29.3 \pm 5.6$ vs. $24.3 \pm 5.4$ between groups. Mean of right ventricular ejection fraction is $29.5 \pm 9.5$ vs. $44.9 \pm 12.2$ between groups. Statistically significant differences were between both the groups ( $p<0.001$ ). TR had $40 \%$ vs. $8 \%$ between Group I and Group II respectively and statistically significant $(\mathrm{p}<0.001)$. In MR had $12 \%$ vs. $2 \%$ in between groups respectively and statistically significant differences between groups $(p<0.05)$.

Table VI

Distribution of right Ventricular ejection fraction between two groups $(n=100)$

\begin{tabular}{lcccccc}
\hline Symptoms & \multicolumn{2}{c}{$\begin{array}{c}\text { Group I } \\
(\mathrm{n}=50)\end{array}$} & & \multicolumn{2}{c}{$\begin{array}{c}\text { Group II } \\
(\mathrm{n}=50)\end{array}$} & p value* \\
\cline { 2 - 3 } & Number & $\%$ & & Number & $\%$ & \\
\hline$<30$ & 32 & 64.0 & & 8.0 & 0.001 \\
$30-50$ & 16 & 32.0 & & 33 & 66.0 & 0.001 \\
$>50$ & 2 & 4.0 & & 13 & 26.0 & 0.002 \\
\hline
\end{tabular}

Group I: With RVI, Group II : Without RVI

*p value were analyzed using Pearson Chi-Square Test.

Table VI showed that $4 \%$ had ejection fraction (>50) followed by $32 \%$ of the patients had (30-50) and $64 \%$ had $(<30)$ in Group I. On the other hand Group II was found that $26 \%$ had ejection

fraction ( $>50$ ) followed by $66 \%$ of the patients had $(30-50)$ and $8 \%$ had $(<40)$. All these were statistically significant between both the groups.

Table VII

Distribution of in hospital outcome study population $(n=100)$

\begin{tabular}{lcc}
\hline Complaints & No. & $\%$ \\
\hline Uneventful recovery & 40 & 40.0 \\
Hypotension & 53 & 53.0 \\
Cardiogenic shock & 27 & 27.0 \\
Acute LVF & 12 & 12.0 \\
Tachyarrhythmia & 12 & 12.0 \\
Complete heart block & 12 & 12.0 \\
1 st degree heart block & 2 & 2.0 \\
Junctional bradycardia & 2 & 2.0 \\
Sinus bradycardia & 29 & 29.0 \\
Sinus tachycardia & 7 & 7.0 \\
Mechanical complication & & \\
Mitral Regurgitation & 7 & 7.0 \\
Post MI angina & 8 & 8.0 \\
Reinfarction & 5 & 5.0 \\
Cardiac arrest & 10 & 10.0 \\
Death & 7 & 7.0 \\
\hline
\end{tabular}


Table VII showed that complication of patients in hospital were $40 \%$ uneventful recovery, 53\% Hypotension, 27\% Cardiogenic shock, 12\% Acute LVF and 12\% Tachyarrhythmia. Brady arrhythmia were $45 \%$, mechanical complications (mitral regurgitation $7 \%$ ) but no VSR, post MI angina $8 \%$, reinfarction $5 \%$, cardiac arrest $10 \%$ and death $7 \%$. In Brady arrhythmia were $12 \%$ Complete heart lock, $2 \% 1^{\text {st }}$ degree heart block, $2 \%$ Junctional heart block, 29\% sinus bradycardia and $7 \%$ sinus tachycardia.

\section{Table VIII}

In hospital outcome between two groups $(n=100)$

\begin{tabular}{lcccccc}
\hline Outcome & \multicolumn{2}{c}{$\begin{array}{c}\text { Group I } \\
(\mathrm{n}=50)\end{array}$} & & \multicolumn{2}{c}{$\begin{array}{c}\text { Group II } \\
(\mathrm{n}=50)\end{array}$} & $\mathrm{p}$ value* \\
\cline { 2 - 3 } & Number & $\%$ & & Number & $\%$ & \\
\hline Uneventful & 15 & 30 & & 25 & 50 & 0.04 \\
recovery & & & & & \\
Bradyarrhythmia & 30 & 60 & 15 & 30 & 0.05 \\
Tachyarrhythmia & 13 & 26 & & 6 & 12 & 0.001 \\
Heart failure & 8 & 16 & 4 & 8 & 0.21 \\
Mechanical & 6 & 12 & 1 & 2 & 0.05 \\
complications & & & & & \\
Cardiogenic shock & 21 & 42 & 6 & 12 & 0.001 \\
Cardiac arrest & 8 & 16 & 1 & 2 & 0.04 \\
Death & 6 & 12 & 1 & 2 & 0.05 \\
\hline
\end{tabular}

Group I: With RVI ,Group II : Without RVI

*p value were analyzed using Pearson Chi-Square Test.

Table VIII showed that o in-hospital outcome of patients had $30 \%$ vs. $50 \%$ between groups respectively and $(\mathrm{p}<0.05)$. Hypotension and cardiogenic shock had $80 \%$ vs. $46 \%$ and $42 \%$ vs. $12 \%$ respectively. These are statistically significant both the groups $(\mathrm{p}<0.001)$. Tachyarrhythmia had $26 \%$ and $12 \%$ respectively and $(\mathrm{p}<0.01)$. Bradyarrhythmia had $60 \%$ vs $30 \%$ respectively $(p<0.005)$. Statistically significant differences were between the groups $(\mathrm{p}<0.01)$. Cardiac arrest had $16 \%$ vs. $4 \%$ between the groups and $(p<0.05)$. Death had $12 \%$ vs. $2 \%$ in Group I and Group II respectively. Statistically significant differences were present $(p<0.05)$. There had mechanical complication $12 \%$ vs $2 \%$ in group I and group II was Statistically significant $(p<0.05)$.

\section{Discussion:}

Identification of right ventricular infarction in acute inferior myocardial infarction in this study was based on clinical findings and electro- cardiographic and echocardiographic changes. Clinically patients had the features of hypotension, raised JVP and clear lung bases. Right sided chest leads were used for diagnosis. It is now established that ST elevation of $\geq 1 \mathrm{~mm}$ in lead V4R.

Assessment and quantification of right ventricular function is difficult and challenging ${ }^{9}$. Nevertheless, an understanding of right ventricular function may be useful in the management of patients with an inferior acute MI that involves the right ventricle. ${ }^{10}$ The extent of involvement of the right ventricle varies in different series and echocardiographic analysis of the right ventricle can shed light on the severity of the disease. ${ }^{11}$ The aim of the present study was to assess the clinical and echocardiographic evaluation of inferior myocardial infarction with or without right ventricular involvement

On admission ECG findings in lead V4R among the patients of 50 were with $\mathrm{RV}$ myocardial involvement (Group I= ST elevation $>1 \mathrm{~mm}$ ) and 50 were without RV myocardial involvement (Group II= ST isoelectric or depression). The ECG remains a crucial tool in the identification and management of acute MI. The analysis of patterns of ST-T segment in right precordial lead V4R may influence decisions regarding treatment strategy. The early and accurate identification of the infarct related artery on the ECG can help to predict the amount of myocardium at risk and guide decisions regarding the urgency of revascularization.

The mean age of Group Group II patients and I were $(54.5 \pm 11.2$ vs $50.2 \pm 13.4$ years. $\mathrm{P}=0.08)$. The highest number of patients was in the age group (50-59) years. One study in Bangladesh found that mean age of their CAD patients to be $53.6 \pm 10.3$ years, ${ }^{12}$ Majority of patients of Group I and Group II (94\% and $92 \%$ respectively) were male. Statistically not significant mean sex difference was found between patients of study group ( $p>0.05)$. The numbers of female patients were less in almost all study. ${ }^{13}$

Among the study patient chest pain was the most common presenting compliant both the Groups (100\% vs $98 \%)$. Followed by breathlessness (60\% vs $24 \%$ ), nausea ( $54 \%$ vs. $58 \%$ ), vomiting ( $90 \%$ vs $86 \%)$, sweating (90\% vs $98 \%)$, syncope ( $60 \%$ vs $20 \%)$ dizziness (70\% vs $28 \%$ ) between Group I andGroup II respectively. There were statistically significant 
difference were in breathlessness, syncope and dizziness between two groups $(\mathrm{p}>0.001)$. The data are similar to the study done ${ }^{12}$.The mean duration of symptoms was 6.9 \pm 3.6 hours in Group I and $8.9 \pm 4.9$ hours in Group II. The difference was statistically significant in two groups $(p<0.05)$. Duration of symptoms was longer in Group I (324) hours than Group II (1-18) hours.

Regarding hemodynamic status, the mean pulse rate was $68.0 \pm 14.7$ vs. $74.8 \pm 14.6$ per minute, systolic blood pressure $94.6 \pm 30.4 \mathrm{~mm}$ of $\mathrm{Hg}$ vs $115.4 \pm 17.8 \mathrm{~mm}$ of $\mathrm{Hg}$ and diastolic blood pressure was found $66.7 \pm 14.8$ vs $73.1 \pm 13.5 \mathrm{~mm}$ of $\mathrm{Hg}$ between groups. Raised JVP had $74 \%$ in Group I and $26 \%$ in Group II. Lungs bases were clear 70\% cases in Group I and $26 \%$ in Group II respectively. All these differences were statistically significant $(p<0.05)$. Echocardiography had been very useful in detecting right ventricular dilatation and segmental wall motion abnormalities characteristic of right ventricular infraction. ${ }^{7}$

In hospital outcomes of inferior myocardial infarction of both groups were 53\% hypotension, $27 \%$ cardiogenic shock, $12 \%$ Acute LVF and $12 \%$ tachyarrhythmia in both groups. In conductive disturbance $45 \%$ that were (12\% Complete heart lock, $2 \% 1$ st degree heart block, $2 \%$ Junctional heart block, $29 \%$ sinus bradycardia) and $7 \%$ were sinus tachycardia. Mechanical complications were (mitral regurgitation $) 7 \%$, post $\mathrm{MI}$ angina $8 \%$, reinfarction $5 \%$, cardiac arrest $10 \%$ and death $7 \%$. Among the studied patients, the most important frequent complications were hypotension followed by sinus bradycardia, cardiogenic shock, arrhythmias, acute LVF and cardiac arrest and death.

Comparison of echocardiography of the left ventricular mean ejection fraction (LVEF) was $50.6 \pm 6.6$ to $53.0 \pm 8.5$ in between Groups respectively $(\mathrm{p}=0.12)$. Left ventricular internal dimension in diastole (LVIDd) was $46.7 \pm 5.5$ to $47.3 \pm 6.1$ respectively between group $(p=0.65)$. $)$. Left ventricular internal dimension in systole (LVIDs) was $34.7 \pm 4.9$ to $35.2 \pm 7.8$ respectively between group $(\mathrm{p}=0.70)$.

Comparison of echocardiography of right ventricular diameter (in diastole) had $29.3 \pm 5.6$ vs. $24.3 \pm 5.4$ between groups. Mean of right ventricular ejection fraction $29.5 \% \pm 9.5 \mathrm{vs} .44 .9 \% \pm 12.2$ between groups.
Statistically significant differences were between both the groups $(\mathrm{p}<0.001)$. Tricuspid regurgitation had $40 \%$ vs. $8 \%$ and mitral regurgitation had $12 \%$ vs. $2 \%$ in between groups respectively and statistically significant differences between groups $(p<0.05)$. That means when right ventricular diameter in diastole increases right ventricular ejection fraction decreases. Anna et al showed left ventricular ejection fraction $\%$ ( $50 \pm 7$ vs. $58 \pm 8$ ), Right Ventricular end diastolic diameter $\mathrm{cm}(3.2 \pm 1.3 \mathrm{vs}$. $2.6 \pm 2.40)$ and TR( $3 / 70$ vs. $21 / 50$ ) respectively. ${ }^{9}$

\section{Conclusion:}

It may be concluded the study that right ventricular involvement is frequent in acute inferior myocardial infarction and patients who exhibits ST elevation in right sided precordial lead V4R have higher hospital mortality and morbidity. Sequelae of right ventricular involvement are from minimal hemodynamic impairment to frank cardiogenic shock. Clinical suspicion of right ventricular involvement should arise from the presence of hypotension, clear lung field, and engorged neck vein in patients with acute inferior myocardial infarction. Echocardiography is a valuable tool to assess right ventricular function and to diagnose right ventricular involvement but ECG may not be diagnostic after 12 hours of onset of chest pain. It has special role in excluding disease entities which may clinically mimic right ventricular involvement. Use of 12-lead ECG including right precordial leads followed by echocardiography can be the optimum strategy in assessment of right ventricular involvement.

\section{Limitations of the study:}

Although the results of the study support the hypothesis, yet this has got some limitation.

This was a nonrandomized trail. Number of study population was limited. These data should be interpreted with caution, because potentially confounding variables influencing mortality are not equally distributed between groups in a registry setting.

\section{References:}

1. Chaturvedi V \& Bhargava B. Health care delivery for coronary heart disease in India - where are we headed? Am Heart Hosp J 2007; 5 : 32-37. 
2. Reddy KS, Yusuf S. Emerging epidemic of cardiovascular disease in developing countries. Circulation 1998; 97: 596-601.

3. Yusuf S, Reddy KS, Ounpuu s \& Anand S. Global burden of diseases, part I: general considerations, the epidemiologic transition, risk factors and impact of urbanization. Circulation 2001; 104: 2746-2753.

4. Yusuf S, Ounpuu S. Tackling the growing epidemic of cardiovascular disease in south Asia. J Am Coll Cardiol 2001; 38 : 688-689.

5. Piazza G, Samuel Z, Goldhaber. The Acutely Decompensated Right Ventricle: Pathways for Diagnosis and Management. Chest 2005; 128: 18361852.

6. Goldstein JA, Vlahakes JG, Verrier ED. The role of right ventricular systolic dysfunction and elevated intrapericardial pressure in the genesis of low output in experimental right ventricular infarction. Circulation 1982; 65: 513-22.

7. Arcy BD, Nanda NC. Two-dimensional echocardiographic features of right ventricular infarction. Circulation 1982; 65: 167-173.

8. Zehender M, Kasper W, kauder E et al. Right ventricular infarction as an independent predictor of prognosis after acute inferior infarction', $N$ Engl $J$ Med 1993; 328: 981-988.

9. Mattioli, A.V. Vandelli, R. Mattioli, G . Doppler echocardiographic evaluation of Right ventricular function in patients with right ventricular infarction $J$ Ultrasound Med 2000;.19 :. 831-836.

10. Burges MI, Bright, Thomas RJ, Ray SG. Echocardiographic evaluation of right ventricular function. Euro J Echocardiography 2002; 3:252-62.

11. Mehta SR, Eikelboom JW, Natarajan MK et al. Impact of right ventricular involvement on mortality and morbidity in patients with inferior myocardial infarction. J Am Coll Cardiol 2001; 37:37-43.

12. Alam MS. Value of right sided precordial lead (V4R) to predict the site of coronary artery lesion in acute inferior myocardial infarction. Thesis (MD Cardiology). 2007; NICVD.

13. Muttalib MA. Correlation of residual ST segment elevation after streptokinase therapy in acute ST elevation myocardial infarction related coronary artery. Thesis (MD Cardiology). 2007; NICVD.

14. Braat $\mathrm{SH}$ et al. Value of ECG in diagnosing right ventricular involvement with acute inferior wall myocardial infarction. British Heart Journal 1983; 49: 368- 372 .

15. Islam MN, Ali MA, Ali M. Spectrum of cardiovascular disease: the current scenario in Bangladesh. Bangladesh Heart $J$ 2004; 19: 1-7.

16. Majumder AAS et al. Right ventricular involvement in acute myocardial infarction: Course, complications, and management -an experience at a teaching Hospital. Journal of Institute of Postgraduate Medicine \& Research 1996; 11: 22-25.

17. Thygesen K, Alpert JS, White HD. Universal definition of myocardial infarction . Euro. Heart $J$ 2007; 28 : 2525-2538

18. Cohn JN, Guiha NH, Broder MI, Limas CJ. Right ventricular infarction: clinical and hemodynamic features. Am J Cardio 1974; 33: 209-220.

19. Erhardt LR et al. Right ventricular involvement in acute myocardial infarction. Euro J Cardiol 1976; 4: 411- 417.

20. Lindqvist $\mathrm{P}$, Calcutteea A, Henein $\mathrm{M}$. Echocardiography in the assessment of right heart function. Euro J Echocardiography 2008; 9: 225-234. 